3) Komori, T and E. Hirai: Kagaku Kōgaku, 32, 154 (1968)

4) Komori, T and E. Hirai: Kagaku Kōgaku, contributed

5) London, A.L. and R. A. Seban: Trans. A.S.M.E., 65, 771 (1943)
6) Longwell, P. A: A. I. Ch. E. Journal, 4, 53 (1958)

7) Nakaide, M: Shokuhin Kōgyō no Reitō, Kōrin Book Co. (1962)

8) Tao, L. C: A. I. Ch. E. Journal, 13, 165 (1967)

HEAT TRANSFER BETWEEN FLUIDIZED BEDS AND HEATED SURFACES* — EFFECT OF PARTICLE SIZE

RYOHEI YAMAZAKI AND GENJI JIMBO

Department of Chemical Engineering, Nagoya University, Nagoya

\begin{abstract}
Heat transfer coefficients between fluidized beds and heating surfaces were experimentally determined by unsteady state method. An equation of the heat transfer coefficient was proposed by considering a simple model. For high velocity of solid particles, experimental results, especially the effect of particle size, were found to be easily explained by the equation.
\end{abstract}

\section{Introduction}

Heat transfer between fluidized beds and heating surfaces has been the subject of many experimental and theoretical studies.

Wicke and Fetting ${ }^{8)}$ have proposed a model, assuming that the heating surface is covered with a gas film and a region in which solid particles circulate. They also back-calculated thickness from their experimental results.

Ziegler et al. ${ }^{97}$ have proposed a mechanism of unsteady state heat transfer for a single particle, assuming that the surface is covered with a relatively thick gas film, and that the temperature of the heating surface is equal to that of gas in the films. And they have obtained the information from their experimental results that the heat transfer coefficient depends upon the solid heat capacity and is independent of the solid thermal conductivity. From theoretical equation, they have also predicted that the effect of solid heat capacity is very small when the residence time of particle is short, and that the maximum Nusselt number is about 7.2.

Mickley and Fairbanks ${ }^{7)}$ have treated these phenomena, considering the mechanism of unsteady state heat transfer for semi-infinite solids. They considered that the medium contributing to heat transfer is not a single particle of the first row on the heating surface but a small group or assembly of particles. However, their model may imply that as residence time approaches zero, the heat transfer coefficient becomes infinite. This is contrary to experimental results. Besides, they have not clearly described the effect of particle size on

* Received on June 21, 1969

Presentet at 34 th Annual Meeting of the Society of Chemical Engineers, Japan, at Tokyo, April 2, 1969 the heat transfer coefficient.

Botterill et al..$^{3,45}$ have also considered unsteady state heat transfer for a single particle which contacts with a heating surface, and computed temperature distribution within a particle by the relaxation method. They obtained the heat transfer coefficient as a function of residence time on the heating surface. However, they obtained experimental values smaller than calculated values. They considered that this inconsistency is due to the gas gap between a heated surface and solid particles and predicted that the "gap is about one tenth of the particle size.

Baskakov $^{2)}$ has adopted a quasi-steady state heat transfer model between a heating surface and a particle, assuming that the heat conduction is controlled only by the thermal resistance between the heating surface and a particle of the first row. From these assumptions, heat transfer coefficients are proportional to effective thermal conductivity between a surface and a particle and inversely proportional to particle size. Since the effective thermal conductivity depends on the thermal conductivity of the solid particle, the use of a particle with considerably different thermal conductivity is expected to have an effect. However, this assumption is contrary to the experimental results of Ziegler ${ }^{9}$, and of Botterill ${ }^{3,4,5}$.

This report also deals with unsteady state heat transfer for a single particle with relatively short residence time on a heating surface and with rather a high velocity. In case of short residence time, a particle of the first row is not too much heated up, so that heat conduction from the theating surface to a particle is controlled only by the thermal'resistance.between them. On the contrary, the particle of the first row is heated 
up and hence heat conduction from it to a particle of the second row cannot be neglected when residence time is long.

\section{Model}

A single spherical particle which has been at a long distance from a heating surface arrives in the region undergoing the effect of the heating surface at time zero and approaches the surface with a velocity. Colliding with the surface, it goes away with the same velocity. The following assumptions are made.

(1). Fluidized particles are spheres of uniform diameter.

(2) Generally, conductivity of a solid particle is sufficiently large compared with that of gas, and solid particles can rotate. Therefore, the thermal gradients in them may be ignored.

(3) In case of short residence time of a particle, heat conduction from a particle of the first row to one in the second row is ignored.

(4) Direction of heat flow is perpendicular to the heating surface and the thermal gradient in the gas between the heating surface and the surface of the particle may be linear.

(5) Radiant heat transfer from the surface to the particle is neglected.

From the previous assumptions and the state as shown in Fig. 1, the fundamental equation may be written.

$$
m c \frac{d t_{i}}{d \theta}=-k_{f} \frac{d t_{g}}{d x} d A
$$

where $\overline{O H}=a-u_{s} \theta+(\delta-x)$

$$
\begin{aligned}
A= & \pi \overline{P H}^{2}=\pi\left\{2(a+\delta)\left(x+u_{s} \theta\right)\right. \\
& \left.-\left(x+u_{s} \theta\right)^{2}-\left(2 a \delta+\delta^{2}\right)\right\} \\
d A= & 2 \pi\left\{(a+\delta)-\left(x+u_{s} \theta\right)\right\} d x
\end{aligned}
$$

according to assumption (4),

$$
\begin{aligned}
\int_{\Delta} \frac{d t_{g}}{d x} d A= & (2 \pi) \int_{A} \frac{t_{i}-t_{s}}{x}\left\{(a+\delta)-\left(x+u_{s} \theta\right)\right\} d x \\
= & 2 \pi\left(t_{i}-t_{s}\right)\left\{\left(a+\delta-u_{s} \theta\right) \ln \left(\frac{\delta}{\delta-u_{s} \theta}\right)\right. \\
& \left.-u_{s} \theta\right\}
\end{aligned}
$$

Replacing $\left(\delta-u_{s} \theta\right) / \delta=\tau$, substituting Eq. (2) into Eq. (1), and integrating Eq. (1) between $\tau=0$ and $\tau=1$, (until the particle arrives at the heating surface)

$$
\frac{t_{i s}-t_{s}}{t_{f}-t_{s}}=\exp \left\{-\frac{2 \pi k_{f} \delta(a+3 \delta / 4)}{m c u_{s}}\right\}
$$

And similarly, in the case of a particle going away

$$
\frac{t_{i \delta}-t_{s}}{t_{i s}-t_{s}}=\exp \left\{-\frac{2 \pi k_{f} \delta(a+3 \delta / 4)}{m c u_{s}}\right\}
$$

According to Eq. (3) and Eq. (4),

$$
\frac{t_{i \delta}-t_{s}}{t_{f}-t_{s}}=\exp \left\{-\frac{4 \pi k_{f} \delta(a+3 \delta / 4)}{m c u_{s}}\right\}
$$

Therefore, the average or mean rate of heat absorption, $q$, for the particle at the heating surface is given by

$$
\begin{aligned}
q & =m c\left(t_{i \delta}-t_{f}\right) \frac{1}{2 \delta / u_{s}} \\
& =\left(t_{s}-t_{f}\right) \frac{m c u_{s}}{2 \delta}\left[1-\exp \left\{-\frac{4 \pi k_{f} \delta(a+3 \delta / 4)}{m c u_{s}}\right\}\right]
\end{aligned}
$$

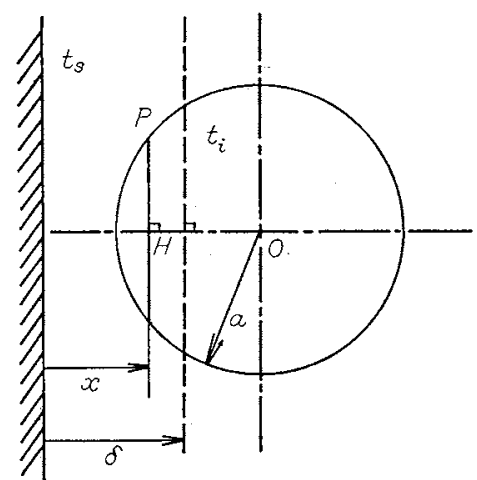

Fig. I Model for heat transfer between a solid particle and a heating surface

Number of particles at the heating surface may be shown as follows:

$$
N=3(1-\epsilon) A^{\prime} / 2 \pi a^{2}
$$

Average rate of heat absorption $Q$ for the particle at the heating surface is given by

$$
Q=N q
$$

while,

$$
Q=A^{\prime} h\left(t_{s}-t_{f}\right)
$$

Eq. (8) is equated to Eq. (9) to yield

$h=(1-\epsilon) \frac{d_{p} \rho_{c} u_{s}}{2 \delta}\left[1-\exp \left\{-\frac{12 k_{f} \delta\left(1+3 \delta / 2 d_{p}\right)}{d_{p}^{2} \rho_{c u_{s}}}\right\}\right]$

or,

$N u=\frac{h d_{p}}{k_{f}}=(1-\epsilon)\left(\frac{1}{\Theta}\right)\left[1-\exp \left\{-6\left(1+\frac{3 \delta}{2 d_{p}}\right) \Theta\right\}\right]$

where, $\quad \frac{k_{f}}{c \rho}=\alpha, \quad 2 \delta / u_{s}=\theta_{r}, \quad \alpha \theta_{r} / d_{p}{ }^{2}=\Theta$,

In particular, when the velocity of the particle $u_{s}$ is quite large (in other words, $\Theta$ is very small), Eq. $\left(10^{\prime}\right)$ is as follows

$$
N u_{\max }=6\left(1-\epsilon^{*}\right)\left(1+3 \delta / 2 d_{p}\right)
$$

\section{Experimental Apparatus and Procedure}

Experimental apparatus is shown in Fig. 2. Fluidization section was an $81 \mathrm{~mm} \mathrm{I}$. D. tube ( $800 \mathrm{~mm}$ height) made of vinyl chloride. Nylon canvas was used as an air distributor (about $10 \mathrm{~mm}$ thickness). Fluidized solids used are shown in Table 1. Experimental procedure was as follows: After a steel ball (diameter: $12 \mathrm{~mm} \phi$, density: $7860 \mathrm{~kg} / \mathrm{m}^{3}$, heat capacity: $0.113 \mathrm{kcal} / \mathrm{kg}^{\circ} \mathrm{C}$, thermal conductivity: $44.6 \mathrm{kcal} / \mathrm{mhr}^{\circ} \mathrm{C}$ ) with a copperconstantan thermo-couple on the surface was heated by a dryer, it was inserted into the fluidized bed and fixed about 10 centimeters above the gas distributor, and the change of surface temperature with time was recorded. The initial surface temperature was between $70^{\circ} \mathrm{C}$ and $80^{\circ} \mathrm{C}$. The copper and constantan wire used for the thermo-couple was $0.3 \mathrm{~mm}$ diameter. Its junction $(0.6$ $\mathrm{mm}$ diameter) was inserted into a hole (depth: 0.6 $\mathrm{mm}$ ) drilled at the surface of the steel ball and was fixed by a synthetic adhesive. 


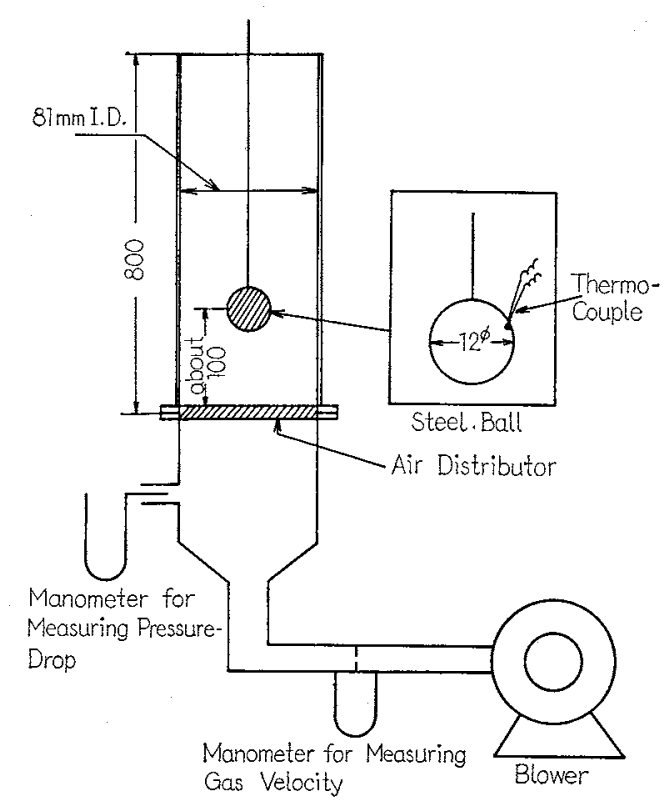

Fig. 2 Experimental apparatus

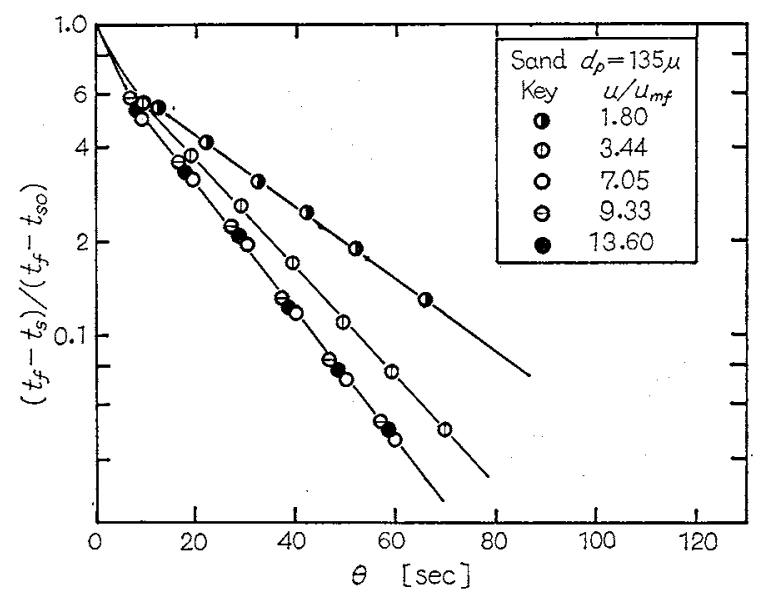

Fig. $3\left(t_{f}-t_{s}\right) /\left(t_{f}-t_{s 0}\right)$ vs. $\theta$

\section{Experimental Results}

Heat transfer coefficients were calculated, Heisslerchart being used. An example of the change of surface temperature with time (sand, $d_{p}=135 \mu$ ) is shown in Fig. 3. Heat transfer coefficients obtained in such a way are plotted as functions of $u / u_{m f}$ in Fig. 4, Fig. 5 and Fig. 6. Fig. 4, Fig. 5 and Fig. 6 are of limestone, molding sand and fused alumina, respectively. The heat transfer coefficient increased as gas velocity increased from the minimum fluidizing velocity, until it arrived at the maximum value. It was shown that larger values of maximum heat transfer coefficient were obtained for smaller particles, and that the heat transfer coefficients increased more rapidly for larger particles. Fig. 7 shows the relationship between maximum heat transfer coeff-

\section{Table I Fluidized solid used}

\section{Lime stone}

range of

\begin{tabular}{cccc} 
particle size $[\mu]$ & mean size $[\mu]$ & $u_{m f}[\mathrm{~cm} / \mathrm{sec}]$ & $\epsilon_{m f}[-]$ \\
\hline $420 \sim 250$ & 310 & 8.20 & 0.440 \\
$250 \sim 177$ & 210 & 4.72 & 0.443 \\
$177 \sim 149$ & 160 & 2.80 & 0.446 \\
$149 \sim 125$ & 135 & 2.06 & 0.474 \\
$125 \sim 104$ & 115 & 1.14 & 0.502 \\
$104 \sim 74$ & 89 & 1.20 & 0.523 \\
$74 \sim 61$ & 68 & 0.86 & 0.520
\end{tabular}

Molding sand

range of

\begin{tabular}{cccc} 
particle size $[\mu]$ & mean size $[\mu]$ & $u_{m f}[\mathrm{~cm} / \mathrm{sec}]$ & $\epsilon_{m f}[-]$ \\
\hline $250 \sim 177$ & 210 & 4.30 & 0.419
\end{tabular}

$\begin{array}{llll}177 \sim 149 & 160 & 3.04 & 0.499\end{array}$

$\begin{array}{llll}149 \sim 125 & 135 & 2.12 & 0.504\end{array}$

$\begin{array}{llll}125 \sim 104 & 115 & 1.32 & 0.499\end{array}$

$\begin{array}{llll}104 \sim 74 & 89 & 1.04 & 0.523\end{array}$

$\begin{array}{llll}74 \sim 61 & 68 & 0.74 & 0.502\end{array}$

Fused alumina

range of

\begin{tabular}{cccc} 
particle size $[\mu]$ & mean size $[\mu]$ & $u_{m f}[\mathrm{~cm} / \mathrm{sec}]$ & $\epsilon_{m f}[-]$ \\
\hline $125 \sim 104$ & 115 & 1.92 & 0.583
\end{tabular}

$\begin{array}{lrrr}125 \sim 104 & 115 & 1.92 & 0.583 \\ 104 \sim 74 & 89 & 1.60 & 0.606\end{array}$

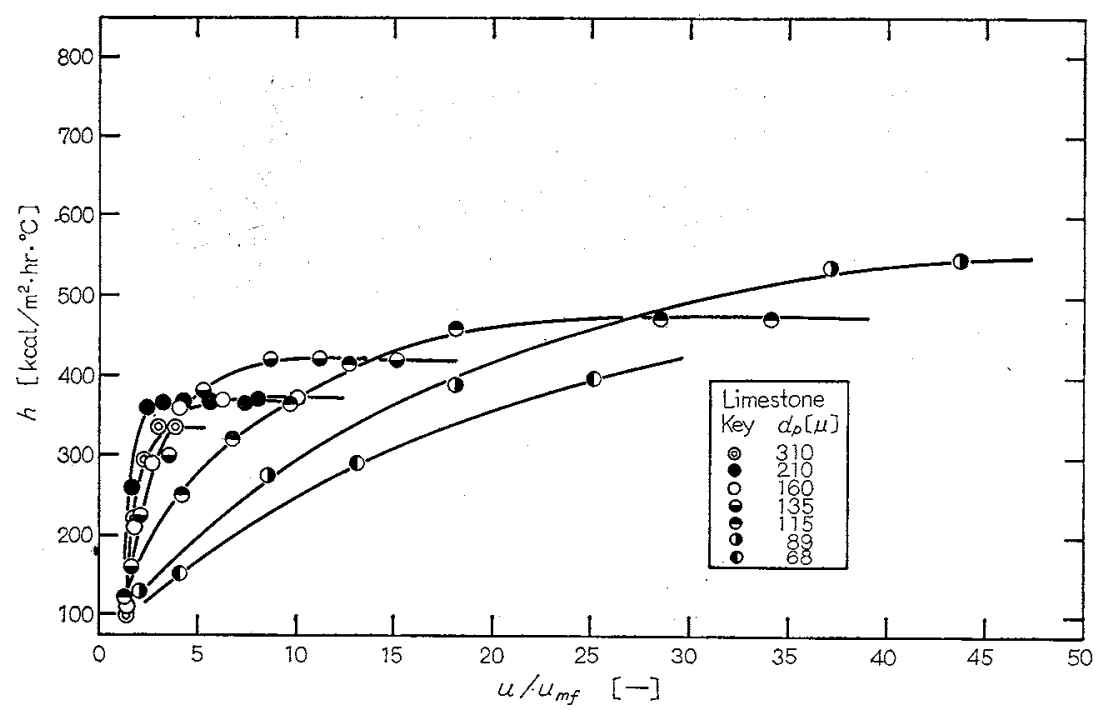

Fig. 4 h vs. $v / u_{m f}$ 


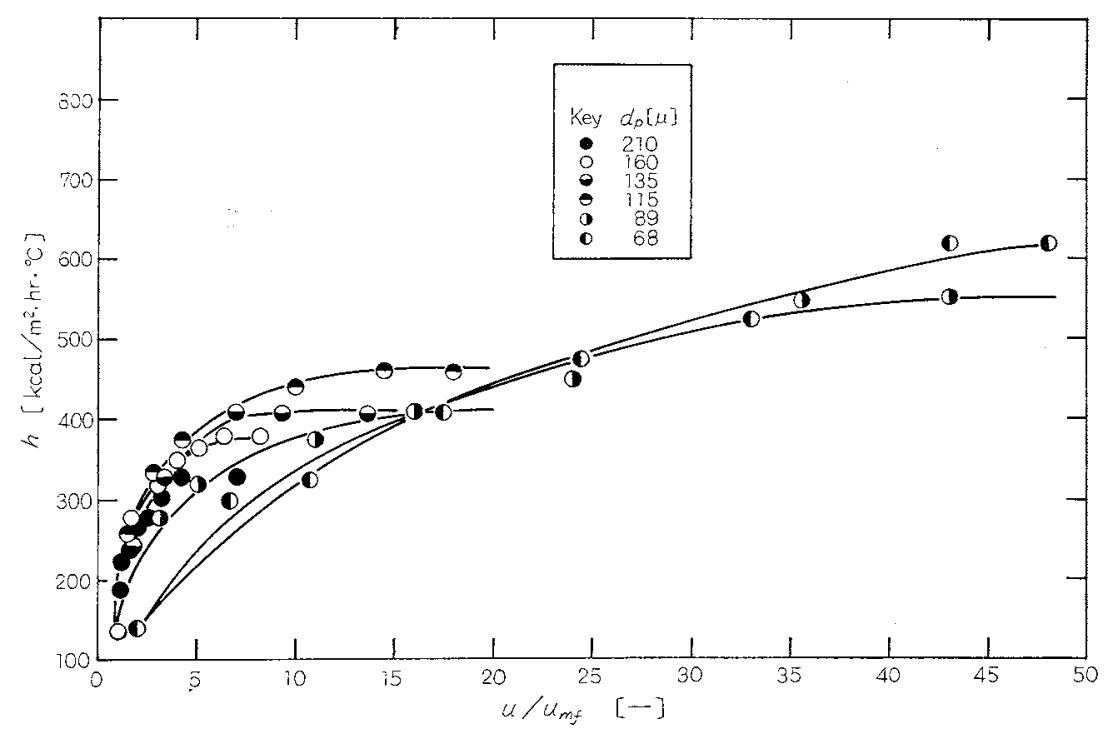

Fig. 5 h vs. $v / u_{m f}$

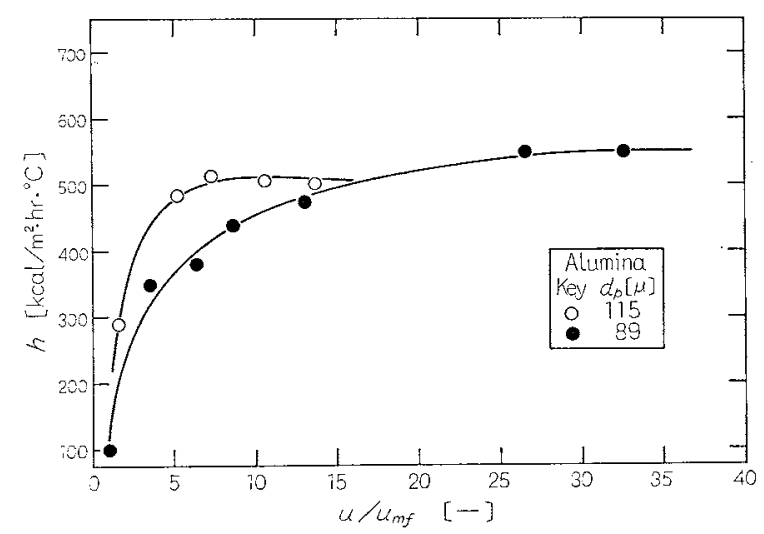

Fig. $6 h$ vs. $u / u_{m f}$

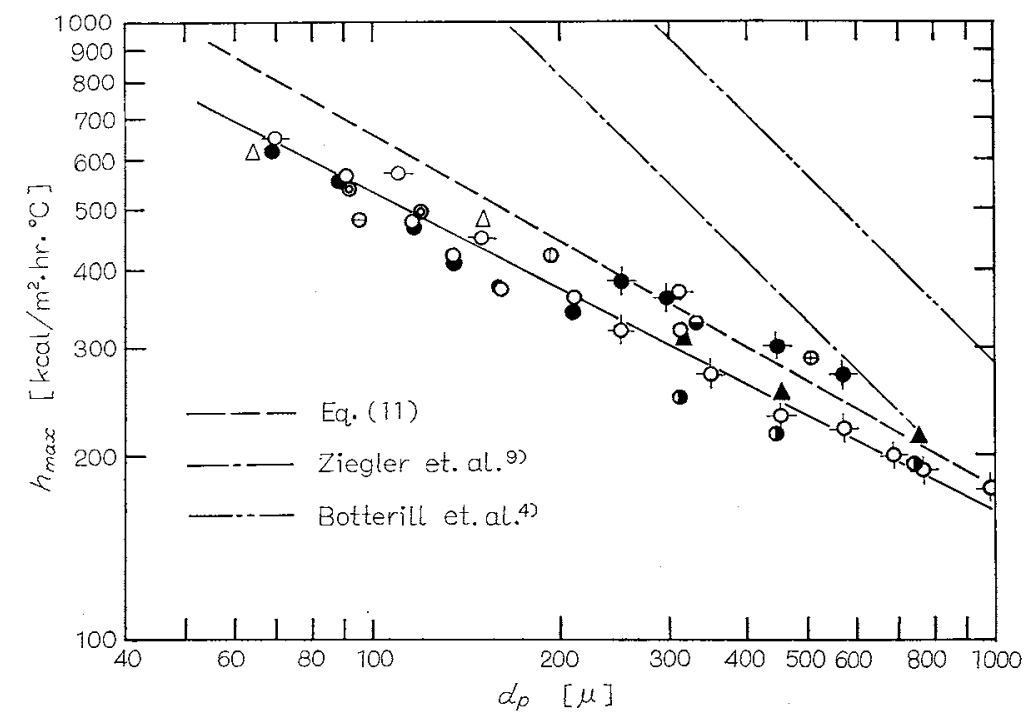

O Limestone

- Molding Sand

() Fused Alumina

(This report) $\theta \mathrm{Al}_{2} \mathrm{O}_{3}$

(1) Iron Powder

- Sand

(Bilica
(Baerg et. al. ")
$\triangle \mathrm{SiC}$
- Activated Carbon

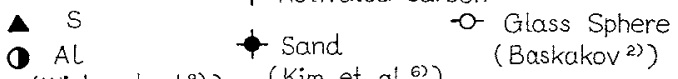

(Wicke et.al.8) (Kim et. al.6)

Fig. 7 Effect of particle size on maximum heat transfer coefficient 


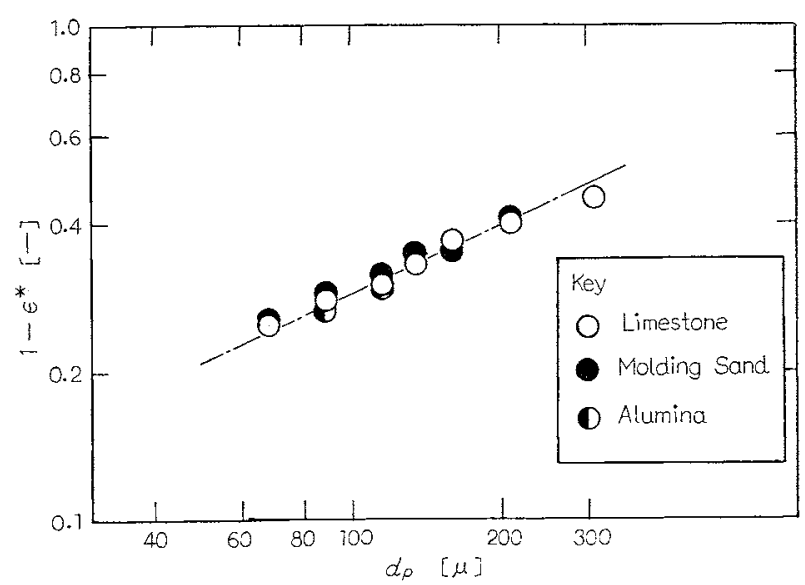

Fig. 8 Relationsphip between porosity at maximum heat transfer coefficient and particle size

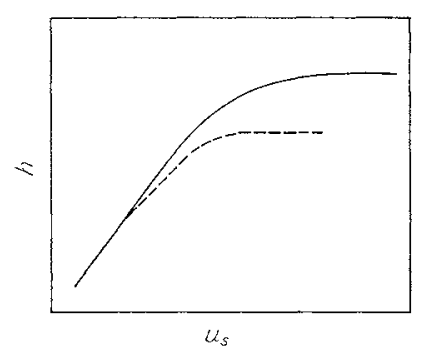

Fig. 9 The relationship between heat transfer coefficient and particle velocity

cient and particle size. Fig. 8 shows the relationship between porosity at the maximum values and particle size.

\section{Discussion}

Theoretical values from Eq. (11) are also shown in Fig. 7. Since $\delta$ is recognized as the thickness of the region in which the particles are affected by the heating surface, $\delta$ may be equated to $d_{p} / 2$. And the relationship of Fig. 8 is adopted for $\left(1-\epsilon^{*}\right)$ in Eq. (11). The calculated line of Ziegler ${ }^{9}$ and that of Botterill et $\mathrm{al}^{4)}$. are also shown in Fig. 7. According to Fig. 7, the calculated values of this report are a little larger than the experimental values. It is considered that the difference between them is due to the possibility of taking smaller value of porosity in Eq. (11). For further consideration, the assumption is questionable that the porosity at the heating surface is equal to the mean porosity of the bed. Although there is some difference between the theoretical and experimental heat transfer coefficient values, the maximum values of the heat transfer coefficients may be concluded to be almost inversely proportional to particle size. However, since $\left(1-\epsilon^{*}\right)$ at the maximum values is nearly proportional to $d_{p}{ }^{1 / 2}$ as shown in Fig. 8, apparently $h_{\max }$ is proportional to $d_{p}^{-1 / 2}$ without considering the effect of porosity. Although no experiment was done for a solid whose thermal properties are considerably different, the effect of the kind of particle on heat transfer coefficients was not noticeable. Therefore, assumption (2) was ascertained to be reasonable in the range of this experiment. Further, the following discussion about the theoretical value of maximum heat transfer coefficient is pertinent. If the porosity of the bed is kept at the point of incipient fluidization, the increase of heat transfer coefficient with solid particle velocity may be shown by the solid line in Fig. 9, as anticipated by Eq. $\left(10^{\prime}\right)$. However, in actual practice both the solid particle velocity and the porosity of the bed increase with superficial fluid velocity. For this reason, the heat transfer coefficient must be shown as the dotted line in Fig. 9. When the increase of porosity with superficial fluid velocity is very large, the heat transfer coefficient reaches the maximum value before the solid particle velocity becomes so large. In this case, as shown by Eq. $\left(10^{\prime}\right)$, the heat transfer coefficient is expected to depend on the density and heat capacity of the solid particle. However, the effect of density and heat capacity of the solid on heat transfer coefficient is not noticeable in these experimental results. Therefore, when the velocity of the solid particle is considered to be sufficiently large, it is confirmed experimentally that Eq. (11) can be adopted in place of Eq. $\left(10^{\prime}\right)$, as is shown in the consideration of this proposed model.

\section{Conclusion}

As a theoretical equation of heat transfer between a fluidized bed and a heating surface, a simple equation was derived theoretically on the basis of a newly proposed unsteady-state model. Also, it is found that this equation, especially the effect of particle size, was confirmed experimentally as was shown in Fig. 7. For high particle velocity, the heat transfer coefficient between fluidized beds and heating surface may be considered to be unaffected by the thermal properties of the particle (thermal conductivity, heat capacity) but by particle size, thermal conductivity of gas and porosity of bed.

\section{Nomenclature}

$A=$ projected area of a sphere against heated surface $\left[\mathrm{m}^{2}\right]$ $A^{\prime}=$ area of heated surface $\left[\mathrm{m}^{2}\right]$

$a=$ radius of spherical solid particle $[\mathrm{m}]$

$c=$ heat capacity of solid particle $\quad\left[\mathrm{kcal} / \mathrm{kg}^{\circ} \mathrm{C}\right]$

$d_{p}=$ diameter of solid particle [m]

$h=$ heat transfer coefficient between fluidzed bed and heated surface $\quad\left[\mathrm{kcal} / \mathrm{m}^{2} \mathrm{hr}^{\circ} \mathrm{C}\right]$

$k_{f}=$ thermal conductivity of gas $\quad\left[\mathrm{kcal} / \mathrm{mhr}^{\circ} \mathrm{C}\right]$

$m$ = mass of solid particles [kg]

$N=$ number of solid particles at heating surface $\quad[-]$
$N u=$ Nusselt number

$Q=$ mean rate of heat absorption of solid particles

$q=$ mean rate absorption of single solid particle $[\mathrm{kcal} / \mathrm{hr}]$

$t=$ temperature $\left[{ }^{\circ} \mathrm{C}\right]$

$u=$ superficial air velocity $\quad[\mathrm{m} / \mathrm{hr}]$

$u_{m f}=$ superficial air velocity at minimum fluidization $[\mathrm{m} / \mathrm{hr}]$

$u_{s}=$ velocity of solid particle $[\mathrm{m} / \mathrm{hr}]$

$x=$ distance measured from heating surface $[\mathrm{m}]$

$\alpha=k_{f} / \rho_{C} \quad\left[\mathrm{~m}^{2} / \mathrm{hr}\right]$

$\delta=$ thickness of region in which a particle is affected by 
heating surface

$=$ porosity of fluidized bed

$\epsilon^{*}=$ porosity of fluidized bed at maximum heat transfer coefficient

$=$ time

$\theta_{r}=$ residence time of particle in the region $\left(=2 \delta / u_{s}\right)[\mathrm{hr}]$

$=\alpha \theta_{r} / d_{p}{ }^{2}$

$=$ density of solid particle

$=\left(\delta-u_{s} \theta\right) / \delta$

Subscript

$=$ gas

$=$ solid particle

$=$ at the time of a particle's arrival at a heating surfacs

$=$ at the time of a particle's passing from a heating surface at a distance $\delta$

$\max =$ maximum value

$f=$ fluidized bed

$s \quad=$ heating surface

$O=$ at time $O$

\section{Literature Cited}

1) Baerg, A., Klassen, J., Gishler, P. E. : Canad. J. Res. Sect., 28,287 (1950)

2) Baskakov, A. P.: Intern. Chem. Engrs., 4, 320 (1964)

3) Botterill, J.S. M., Williams, J.R.: Trans. Instn. Chem. Engrs., 41, 217 (1963)

4) Botterill, J. S. M., Butt, M. H. D., Cain, G. L., Redish, K. A.: International Symposium on Fluidization, 442 (1967)

5) Botterill, J. S. M., Butt, M. H. D., Cain, G. L., Chandraseknar, R., Williams, J. R.: International Symposium on Fluidization, ibid, 458 (1967)

6) Kim, K. J., Kim, D. J., Chun, K. S., Choo, S. S.: Intern. Chem. Engrs., 8, 472 (1968)

7) Mickley, H. S., Fairbanks, D. F.: A. I. Ch. E. Journal, 1, 374 (1955)

8) Wicke, E., Fetting, F. : Chemie-Ing. -Techn., 26, 301 (1954)

9) Ziegler, E. N., Koppel, L. B., Brazelton, W. T.: I. \& EC, Fundamentals, 3, 324 (1964)

\title{
THE APPLICABILITY OF THE PSEUDO-STEADY STATE APPROXIMATION TO MOVING BOUNDARY PROBLEMS FOR SPHERES ${ }^{*}$
}

\author{
MASARU ISHIDA, KISHIO YOSHINO AND TAKASHI SHIRAI \\ Tokyo Institute of Technology, Research Laboratory of \\ Resources Utilization, Tokyo, Japan
}

\begin{abstract}
The equations of diffusion and heat transfer for moving boundary problems in spherical particles were computed in order to test the applicability of the pseudo-steady state approximation, which is usually believed to be valid for the case of gas diffusion. This approximation, however, may sometimes induce considerable errors for the case of heat transfer.

In this study, figures are presented to test such applicability in the literature data and further to correct the experimental data under those conditions.
\end{abstract}

\section{Introduction}

The formation of ice, the melting of solids, the drying of porous materials during the second fallingrate period, the thermal decomposition of solids, and many other solid-gas reactions are often treated as problems of moving boundaries, i. e., (1) a clear boundary always exists between the unreacted core and the reacted layer, (2) the reaction and the phase change take place only at the surface of this boundary, and (3) through the reacted layer the gas diffuses and the heat is transferred.

The analysis of the above-mentioned phenomena for spherical particles can be started from the following partial differential equations for diffusion and heat transfer, respectively.

$$
\varepsilon \frac{\partial C_{A}}{\partial t}=\nabla\left(D_{e A} \nabla C_{A}\right)
$$

\footnotetext{
* Received on April 18, 1969
}

$$
C_{T} \hat{C}_{p T} \frac{\partial T}{\partial t}=\nabla\left(k_{e} \nabla T\right)
$$

with the following initial and boundary conditions,

$$
\left.\begin{array}{lll}
D_{e A} \nabla C_{A}=a C_{S o}\left(-\frac{d r_{c}}{d t}\right) & & \\
\text { or } \quad k_{e} \nabla T=C_{S o}\left(\Delta H_{S}\right)\left(-\frac{d r_{c}}{d t}\right) & \text { at } r=r_{c} \\
r_{c}=R & \text { at } t=0
\end{array}\right\}
$$

Since exact analytical solutions of Eqs. (1) and (2) are impossible except for flat plate, they are often solved under the pseudo-steady state (P. S. S.) approximation, in which the moving rate of the boundary within the solid is assumed to be far slower than the rate of diffusion and heat transfer, and accordingly the left-hand terms of Eqs. (1) and (2) are negligible.

Several investigators have studied and discussed the applicability of the P. S. S. approximation. Pekeris and Slichter ${ }^{7}$ applied the perturbation method to the problem of freezing soil around the external surface of a long cylinder, and derived an approximate solution which showed that the maximum error to be introduced by 